\title{
APRENDIZAGEM ORGANIZACIONAL E MOTIVAÇÃO HUMANA: UMA RELAÇÃO SISTEMICAMENTE REPRESENTADA
}

\author{
Data de submissão: 30/05/2016 \\ Aceite: $24 / 09 / 2017$ \\ Giovanna Garrido ${ }^{1}$ \\ Adriana Vazzoler Mendonça² \\ Marco Antonio Silveira ${ }^{3}$
}

\section{RESUMO}

Este estudo visa atribuir às análises sobre a aprendizagem organizacional um viés subjetivo, objetivando explorar as principais relações de causalidade entre a aprendizagem e a motivação no contexto organizacional. Classificado como pesquisa bibliográfica de cunho psicológico e sociológico, o estudo se sustentou, predominantemente, em referenciais disponíveis nas bases Scielo e Proquest. A solidez do debate garantiu-se pela ancoragem do estudo a duas bases argumentativas que, pela subjetividade analítica aqui proposta, foram julgadas influentes no processo abordado: a essência humana e o sentido encoberto do trabalho. Com base na consideração dessas duas bases e na metodologia adotada, construiu-se um mapa sistêmico incluindo as principais variáveis que circundam a relação entre os fenômenos aprendizagem e motivação, denotando a natureza desta relação e a forma como, relacionados, impactam na produtividade do trabalho e no desempenho das organizações. O mapa construído mostrou-se pertinente por possibilitar uma melhor interpretação das relações causais e das influências recíprocas, direta ou inversamente proporcionais, entre as variáveis de interesse, subsidiando decisões e servindo de orientação aos gestores envolvidos nos processos de aprendizagem organizacional.

Palavras-chave: Aprendizagem organizacional. Motivação. Desempenho. Gestor educador. Sustentabilidade.

\footnotetext{
1 Possui graduação em Gestão Empresarial pela Faculdade de Tecnologia de Americana (Fatec), mestrado em Engenharia de Produção pela Universidade Federal de São Carlos (UFSCar). Pesquisadora bolsista do Programa de Capacitação Institucional (PCI) do Centro de Tecnologia da Informação Renato Archer. Campinas - SP. Brasil. E-mail: giovanna.garrido@cti.gov.br

2 Possui graduação em Arquitetura e Urbanismo pela Pontifícia Universidade Católica de Campinas (PUC Campinas) e em Psicologia pela Anhanguera Educacional em Campinas, SP. Pós-graduada em Gestão da Qualidade e Gestão de Negócios. Foi pesquisadora do Centro de Tecnologia da Informação Renato Archer. Atualmente trabalha com neurofeedback e mentoria para pessoas com altas habilidades/superdotação. Campinas - SP. Brasil. E-mail: adriana.italia@gmail.com

3 Possui graduação em Engenharia Elétrica pela FEB, mestrado em Engenharia Elétrica pela Universidade Estadual de Campinas, UNICAMP e doutorado em Processos de Fabricação pela UNICAMP, é membro permanente do corpo docente do programa de mestrado e doutorado em Administração da UNIFACCAMP, sendo desde 2012 pesquisador CNPq de alta produtividade nível DT-2. Campinas - SP. Brasil. E-mail: marco.silveira@cti.gov.br
} 


\section{INTRODUÇÃO}

Nas últimas décadas, frente às mudanças no cenário organizacional global e ao reconhecimento do capital intelectual como um ativo estratégico das organizações, muito se é debatido acerca do fenômeno da aprendizagem, ressaltando a sua relevância para a inovação e a sustentabilidade organizacional e postulando-o como um processo positivamente relacionado ao desempenho das organizações (KOFMAN, 2004; SILVEIRA, 2013b; SILVEIRA; MAIA; FIORAVANTI, 2012).

Contudo, por se tratar de um fenômeno que envolve interações entre fatores organizacionais e humanos, uma ação que procede de seus comportamentos, nota-se que a compreensão dos mecanismos humanos internos requer um viés analítico subjetivo, considerando os efeitos que a aprendizagem gera no indivíduo de forma que influencie a propensão individual à melhoria de desempenho e ao próprio processo de aprender.

Nesse contexto, por sua essencialidade na construção do entendimento do processo de aprendizagem no contexto organizacional, o artigo denota a motivação como o elemento intermediário que subsidia e sustenta a consideração do aprendizado como estratégia de melhoria do desempenho no trabalho. Assim sendo, todas as argumentações estruturadas no artigo procuram contribuir para a compreensão sobre as principais relações de causalidade entre a aprendizagem e a motivação no contexto organizacional, de forma que esta dinâmica possa ser mais bem conhecida e, assim, subsidiar a sua gestão de modo a atender às necessidades das pessoas e das organizações.

Direcionado a esta problemática, busca-se neste artigo explorar os fatores subjacentes à aprendizagem e à motivação, com o objetivo de construir um mapa sistêmico incluindo as principais variáveis que circundam a relação entre os dois fenômenos, denotando a natureza desta relação e a forma como, relacionados, impactam na produtividade do trabalho e no desempenho das organizações.

Por meio de tal metodologia, busca-se propiciar uma reflexão e interpretação das relações causais e das influências recíprocas representadas. A própria lógica sobre a qual o mapa se desenvolve é a de criar condições para que, ao atuar nos processos das relações entre elas, cada uma das variáveis floresça, podendo, assim, subsidiar as tomadas de decisões e servir como um meio de orientação aos gestores envolvidos nos processos de aprendizagem organizacional, os quais podem concretamente ativar as capacidades humanas (SENGE, 2004).

A fim de atender a esta proposta, o artigo está estruturado da seguinte forma: inicialmente, será demonstrado o método como o estudo foi conduzido; depois, será apresentado o referencial teórico subdividido em quatro tópicos principais. Primeiramente, é feita uma discussão introdutória sobre a dimensão humana no cenário de alta competitividade global. Em seguida, é discutida a importância de se considerar a subjetividade humana na compreensão da relação entre o aprendizado e o desempenho no trabalho. O terceiro tópico traz a discussão central do artigo introduzindo a essencialidade da motivação intrínseca no processo de aprendizagem e desenvolvendo a lógica sistêmica das relações estabelecidas entre ambos os fenômenos. No quarto tópico, com vistas à sua utilização como conhecimento aplicado, busca-se traduzir toda a interpretação sistêmica entre aprendizagem e motivação como orientações aos gestores envolvidos no processo de aprendizagem. Por fim, apresentam-se as conclusões alcançadas no estudo. 


\section{METODOLOGIA}

O estudo foi realizado por método qualitativo, visando abordar o objeto da pesquisa sem a preocupação de medição ou quantificação dos dados obtidos.

Em relação à classificação do estudo, foi estabelecida como base a taxionomia de Vergara (2009) e os quesitos de classificação de Gil (2002). Quanto aos fins, a pesquisa pode ser caracterizada como exploratória e descritiva. Exploratória, pois além de ter um intuito de trabalho diferenciado com os fenômenos da aprendizagem e da motivação, específico à construção do mapa sistêmico, a proposta do artigo foi direcionada ao aprimoramento de ideais e à descoberta de intuições concernentes ao problema, visando torná-lo mais explícito. Descritiva, pois, por meio do que propôs, intuiu a descoberta e a representação de relações que ocorrem entre variáveis com a pretensão de determinar a sua natureza.

Quanto aos meios, o estudo foi bibliográfico de cunho psicológico e sociológico, sustentado, predominantemente, por referenciais teóricos disponíveis em periódicos indexados nas bases Scielo e Proquest. Embora em menor proporção, também foram consultados livros, artigos de congressos e outros periódicos não indexados em tais bases, os quais se mostraram pertinentes tendo em vista o conteúdo e o caráter da pesquisa

Assim, mediante todo o aparato teórico, foram investigados os fundamentos norteadores dos fenômenos da aprendizagem e da motivação no contexto organizacional, com vistas a delimitar as principais variáveis que norteiam a relação entre ambos. É válido considerar que a solidez desta investigação promovida pelo estudo foi garantida ancorando-o a duas bases teóricas presentes na literatura que, pela subjetividade analítica aqui proposta, foram julgadas como fatores influentes no processo abordado: a essência humana e o sentido encoberto do trabalho.

A consideração dessas bases teóricas subsidiou toda a lógica desenvolvida para o cumprimento dos objetivos deste estudo. Com base em hipóteses, intuições e no próprio conhecimento especializado acerca das relações recíprocas estabelecidas entre as variáveis de interesse, construiu-se um mapa sistêmico incluindo as principais variáveis que circundam a relação entre os fenômenos aprendizagem organizacional e motivação, denotando a causalidade que se estabelece entre eles e a forma como, relacionados, impactam na produtividade do trabalho e no desempenho das organizações.

\section{REFERENCIAL TEÓRICO}

\subsection{O DESENVOLVIMENTO HUMANO E O CENÁRIO COMPETITIVO}

O cenário econômico do século XXI tem exigido das organizações o desenvolvimento de competências para sobreviver em um ambiente mundial altamente competitivo. Os paradigmas que resultaram em sucesso até aqui podem não produzir novos sucessos, exigindo a aquisição de novos conhecimentos em busca de melhor desempenho e maior compreensão das dinâmicas do mercado. Tanto na academia como nas organizações, almeja-se uma economia que leve em conta as pessoas, que conduza a tecnologia de volta à escala humana, uma vez que o lucro pelo lucro tem se tornado uma estratégia de alto risco.

Nesse contexto, a noção de capital intelectual tem se tornado o principal ativo das organizações. A questão é que, resultantes das próprias alterações mercadológicas, novas práticas 
de trabalho surgiram e, com elas, uma nova visão ao seu respeito. Trabalhadores das novas gerações preferem engajar-se em atividades que estejam de acordo com seus próprios valores, que sejam condizentes com os recursos naturais disponíveis, que respeitem os limites de todos os envolvidos e que façam sentido para todos. Assim, como responsáveis pela geração do capital, dá-se a necessidade de alinhar seus interesses com os da organização (CHIUZI; PEIXOTO; FUSARI, 2011; ROCHA-DE-OLIVEIRA; PICCININI; BITENCOURT, 2012; VELOSO; SILVA; DUTRA, 2012).

Desde os primórdios das relações de emprego, a organização e o trabalhador participam de uma relação simbiótica, em que um não existe sem o outro, e que o comportamento de um modifica o comportamento do outro. Isto é, as organizações são ambientes de transformação humana, e os homens são agentes transformadores das organizações. Deste modo, pode-se considerar que a partir do momento em que a organização disponibiliza boas condições de trabalho para o trabalhador, maiores são as chances de o trabalhador responder com enriquecimento do capital humano disponibilizado para a organização (SILVEIRA et al., 2015).

Assim, somadas as demandas em favor da competitividade e da qualidade de vida dos trabalhadores, as organizações se veem diante da necessidade de concentrar seus esforços para o alcance de uma postura sustentável no mercado. Vale considerar que, não somente para atender às demandas presentes, a busca pela sustentabilidade organizacional tem subjacente a busca da perenidade dos resultados positivos dos negócios, ou seja, de sucesso futuro (SILVEIRA, 2012).

A respeito disso, vale a consideração de que é possível alcançar a sustentabilidade dos negócios e, ao mesmo tempo, manter a qualidade de vida dos trabalhadores quando a organização se atenta a três quesitos que são as bases para a geração contínua do capital humano, a saber: trabalho, capacitação e desenvolvimento pessoal. É evidente que, frente às constantes mudanças do cenário socioeconômico e às necessidades de aumento do desempenho das organizações, o fenômeno da aprendizagem tornou-se uma questão em voga no campo dos estudos organizacionais (SILVEIRA; MAIA; FIORAVANTI, 2012).

Além de consistir em um instrumento de capacitação no trabalho, a aprendizagem também se porta como uma estratégia para o desenvolvimento pessoal. Isso porque, ao mesmo tempo em que é meio para se chegar à produtividade e à sustentabilidade, ela interage com a subjetividade humana, satisfazendo as necessidades intrínsecas de identidade, reconhecimento, confiança e significado do trabalho.

Em síntese, pode-se postular que o aprendizado organizacional contribui significativamente para a geração de capital humano, porém tal alegação não é suficiente para abordar o fenômeno em sua totalidade. Cabe considerar que a compreensão da relação entre a aprendizagem e seus resultados no contexto organizacional depende da consideração de seus efeitos na subjetividade daquele que a recebe. Como um direcionamento à argumentação proposta neste artigo, vale enfatizar o argumento de Pink (2010) de que o capital humano necessita da motivação intrínseca para florescer, um elemento inerente ao aprender organizacional (GODOI; FREITAS; CARVALHO, 2011).

\subsection{Os reflexos da aprendizagem na subjetividade}

Como se pode notar, muito se é debatido acerca das questões relacionadas à aprendizagem no contexto organizacional, postulando-a como um modo de gestão que mobiliza os trabalhadores a melhores resultados no trabalho e como um fenômeno que estabelece uma relação positiva com o desempenho do indivíduo na execução de suas tarefas.

Porém, sustentando-se nos argumentos de Godoi, Freitas e Carvalho (2011), admite-se 
que a aprendizagem é um fenômeno que integra processos cognitivos (pensamentos, percepções e crenças), afetivos (sentimentos e emoções) e pulsionais (ideias e inconsciente). Desta forma, tratando-se de um relacionamento causal entre um fenômeno que tem como enfoque o ser humano e uma ação que procede da postura do mesmo, a compreensão da essência da relação entre a aprendizagem e desempenho requer um viés analítico subjetivo, considerando o indivíduo que atua como o elemento intermediário desta relação.

Afinal, segundo Dejours (2004), a verdadeira essência do trabalho não pertence ao mundo visível e objetivo. $O$ que é medido no trabalho é aquilo que é materializado, mas que não tem nenhuma proporcionalidade que pode ser comparada com o trabalho efetivo. Parte do trabalho efetivo se encontra em uma sombra, em um repositório subjetivo. Assim, para entender a essência do trabalho é necessário desvendar aquilo que se revela da subjetividade.

Deste modo, julga-se necessário analisar as tensões e ambiguidades entre o que é objetivo e o que é subjetivo na relação entre aprendizagem e desempenho. A necessidade reside em considerar os efeitos subjetivos que a aprendizagem gera no indivíduo de forma que, acrescendo a sua motivação, influencie a propensão individual a uma melhoria de desempenho e ao próprio processo de aprender.

É válido considerar que a garantia de uma maior solidez para este debate requer ancorá-lo a duas bases argumentativas presentes na literatura que, pela subjetividade analítica aqui proposta, podem ser julgadas como fatores influentes no processo abordado: a essência humana e o significado encoberto do trabalho. Aliás, a ancoragem a estas bases não é simplesmente válida. Segundo Dejours (2004), a associação entre a subjetividade do indivíduo com a ação que pratica só é permitida por meio da análise precisa da relação entre o trabalho e a vida deste indivíduo.

\subsubsection{A essência humana}

Tratando-se da análise dos efeitos subjetivos ocasionados pelo desenvolvimento de competências, é válido afirmar que o trabalhador, como um ser individual ativo, é interiorizado por sentimentos e ambições que o fazem criar expectativas e envolver-se na busca pelo crescimento dentro daquilo que realiza, em um contínuo esforço para integrar suas experiências de forma coerente com a sua própria vontade (MORETTI; TREICHEL, 2003; TÉLLEZ, 2012).

$\mathrm{O}$ aprendizado ocupa um lugar preponderante no desenvolvimento humano e permeia todas as fases da vida (SILVEIRA; MAIA; FIORAVANTI, 2012). Segundo Senge (1990), é característico do ser humano vir desde a sua infância equipado com o insaciável desejo de explorar, experimentar, conhecer. Seu desejo pelo aprendizado é um impulso para ser generativo, é uma motivação intrínseca, uma autoestima, uma curiosidade inata em aprender e expandir as suas capacidades.

Pode-se afirmar que o indivíduo, como um ser integrado e indivisível, é levado, pressionado e motivado a reduzir ou satisfazer as suas necessidades interiores. Envolto e impelido pelos sonhos de autoestima, autodesenvolvimento e autorrealização, suas ações se dirigem à satisfação das necessidades concernentes ao seu próprio ego (BENDASSOLLI, 2009; MORETTI; TREICHEL, 2003).

Assim, deve-se deixar de lado a ideia de que o homem realiza suas tarefas apenas para a obtenção de salário, que ele nega seus próprios sentimentos e não se frustra com a falta de crescimento. A demanda por competências é um elemento característico da própria essência humana e desempenha um papel central na vida dos seres humanos. A necessidade de sentir-se 
competente e capaz de conseguir o que se propõe é inerente ao indivíduo, e é a promoção deste sentimento que fortalece a sua motivação intrínseca (MORETTI; TREICHEL, 2003; SANT'ANNA; MORAES; KILIMNIK, 2005; SILVEIRA; MAIA; FIORAVANTI, 2012; TÉLLEZ, 2012).

Fonseca (2014) corrobora afirmando que, se as suas funções conativas estiverem disponíveis e explícitas, visto a influência dos processos emocionais na aprendizagem, o ser humano é considerado a espécie que mais depende da aprendizagem. Em outras palavras, ele nasce para aprender.

\subsubsection{Os sentidos encobertos do trabalho}

Referenciar-se à base teórica que explora a noção do significado e do sentido que o trabalho exerce na vida das pessoas também é válido para a compreensão dos efeitos que o enriquecimento cognitivo das tarefas gera naquele que as executa e o induz à motivação. Assim sendo, a questão acerca dos sentidos encobertos do trabalho atua como outra âncora argumentativa para o debate construído neste estudo. É fato que o trabalho assume dimensões significativas na vida dos indivíduos (MORETTI; TREICHEL, 2003), ao ponto de ser possível considerá-lo como uma das dimensões mais importantes da subjetividade humana (BENDASSOLLI, 2009).

Como um ser único, dotado de uma vida interior e de dinâmicas psíquicas singulares, pode-se dizer que o sujeito é apropriado psicologicamente pelo trabalho que realiza (BENDASSOLLI, 2009). De acordo com Santos (2015), o trabalho é o que permite o indivíduo expressar a sua subjetividade e, ao mesmo tempo, a construir. Vale dizer que a autora sustenta seus ideais tendo como base o trabalho de um escultor. Segundo ela, a ligação que este profissional tem com seu trabalho e com todos os seus recursos permite que ele conheça o resultado daquilo que fará, inclusive o cheiro. Isso porque o conhecimento do seu trabalho faz parte do que ele é. A escultura, por consequência, é aquilo que expressa o seu interior, como um jogo de dentro para fora.

Segundo Dejours (2004), o trabalho é uma ocasião oferecida para a subjetividade se testar e até mesmo para se realizar. É no trabalho que o indivíduo a coloca em prova. É por este motivo que Bendassolli (2009) enfatiza que o trabalho pode ser visto como um processo de autorreflexão, ou seja, um processo de construção inerente ao indivíduo e aos seus estados psicológicos internos pelo qual ele atribui significado, interpreta e dá coerência às suas próprias experiências singulares de vida.

Como se nota, o trabalho é a condição transcendental absoluta da vida, uma prova eletiva na qual ela se revela para ela mesma (DEJOURS, 2004). É o trabalho que propicia ao indivíduo um posicionamento temporal que o faz capaz de acompanhar o seu processo de desenvolvimento e a sua movimentação rumo aos ideais e desejos. $O$ trabalho se porta como um roteiro pessoal para a satisfação de suas próprias necessidades, um veículo por meio do qual o indivíduo se autorrealiza e se autoconceitua (BENDASSOLLI, 2009).

\subsubsection{Identidade humana integrada ao trabalho}

Diante do exposto, pode-se considerar o trabalho como uma fonte de significação para o indivíduo. Ancorando-se à teoria psicanalítica de Morgan (2007), é possível estabelecer que, pela sua proximidade com a subjetividade humana, o trabalho tem para o indivíduo um efeito de objeto transicional. É ele que o simboliza e faz a intermediação entre o sujeito e o mundo com o qual se relaciona.

Deste modo, é válido inferir que é por meio de sua relação com o trabalho que o indiví- 
duo constrói a sua própria identidade. É por este motivo que Dejours (2004) afirma que trabalhar não é apenas produzir, mas transformar a si mesmo. Em concordância, Bendassolli (2009) se fundamenta na Psicologia e argumenta que é de acordo com a apropriação e interpretação dos significados e das informações que recebe que o indivíduo constrói a si mesmo.

Todavia, vale ressaltar que, como um elemento integrador da identidade humana que prova a própria subjetividade daquele que o executa, o trabalho é uma provação que a transforma. Isso quer dizer que ele pode enaltecê-la e acrescentá-la ou diminuí-la e mortificá-la, dependendo da forma como a parte do trabalho que provém dela for considerada, reconhecida e respeitada (DEJOURS, 2004).

Somadas as contribuições de ambas as bases teóricas aqui apresentadas, postula-se que, graças ao seu importante papel na vida humana, o aprendizado no trabalho, para o trabalho e decorrente do trabalho, uma vez que enriquece o repertório individual de conhecimentos, habilidades e atitudes, pode ser considerado uma fonte de realização, satisfação e motivação para o trabalhador (SILVEIRA; MAIA; FIORAVANTI, 2012).

\subsection{APRENDIZAGEM ORGANIZACIONAL E MOTIVAÇÃO HUMANA: UMA RELAÇÃO SISTEMICA- MENTE REPRESENTADA}

Conforme debate estabelecido anteriormente, para melhor entender a relação que se estabelece entre a aprendizagem organizacional e o desempenho no trabalho é necessário primeiro analisar os efeitos que este processo gera no indivíduo, para que assim se possa inquirir sobre a melhor mobilização deste para o trabalho.

Dentre os efeitos subjetivos do desenvolvimento de competências, cuja denotação é o principal fator a ser analisado neste artigo, está a motivação. Segundo Kelloway e Barling (2000), além de aprimorar os conhecimentos e habilidades do trabalhador, o aprendizado tem o potencial de contribuir para a sua motivação intrínseca. Aliás, parte dela provém do fato de que, uma vez inserido em um processo de aprendizagem, o indivíduo tem ciência de que exerce um papel importante na organização e que outras pessoas se importam com ele (MORETTI; TREICHEL, 2003). O próprio sentimento de ser capaz já se porta como um importante construto motivacional com poder de influência nas reações emocionais (PARKER, 1998).

Assim, a consideração deste fenômeno é essencial na construção do entendimento do processo de aprendizagem no contexto organizacional, pois, além de se tratar de um estado psicológico do qual provêm os motivos, a força e a determinação para cada ação humana, a motivação engloba o interesse, o esforço, a persistência e o comprometimento afetivo com o aprender (GODOI; FREITAS; CARVALHO, 2011; KIKUCHI; SALES; TARRAGÔ, 2013; NAQUIN; HOLTON, 2002). Deste modo, é uma questão a ser mencionada neste estudo como o elemento intermediário que subsidia a consideração difundida na realidade organizacional acerca da atuação do aprendizado como estratégia de melhoria do desempenho no trabalho.

De início, é válido estabelecer que entre a aprendizagem e a motivação existe uma relação íntima e contínua de difícil separação (GODOI; FREITAS; CARVALHO, 2011). McCloy e Wise (2002) enfatizam que a motivação no processo de aprendizagem consiste em uma variável importante para as organizações que buscam melhorias no desempenho individual. Segundo Moretti e Treichel (2003), a produtividade não depende estritamente de questões hábeis e conhecimentos aprimorados, mas da somatória destas questões com a motivação do indivíduo e a percepção de seu papel na organização. Com base nestes pareceres, cabe a consideração de que, embora trazida como um efeito subjetivo do desenvolvimento de competências, a motivação também 
se porta como um elemento necessário para que o aprendizado aconteça, sendo diretamente relacionada aos resultados do processo. É ela que habilita a geração e a transferência de conhecimentos. A motivação é necessária para aprender e ela está sempre relacionada a uma base cognitiva e afetiva (KLEIN; NOE; WANG, 2006; OSTERLOH; FREY, 2000; SALLA, 2012; WEISSBEIN et al., 2011).

Deste modo, visando melhor representar a relação que se estabelece entre a aprendizagem e a motivação no contexto organizacional, na Figura 1 é demonstrado um mapa sistêmico incluindo as principais variáveis que as circundam, denotando a causalidade que se estabelece entre os dois fenômenos e a forma como, relacionados, impactam na produtividade do trabalho e no desempenho das organizações.

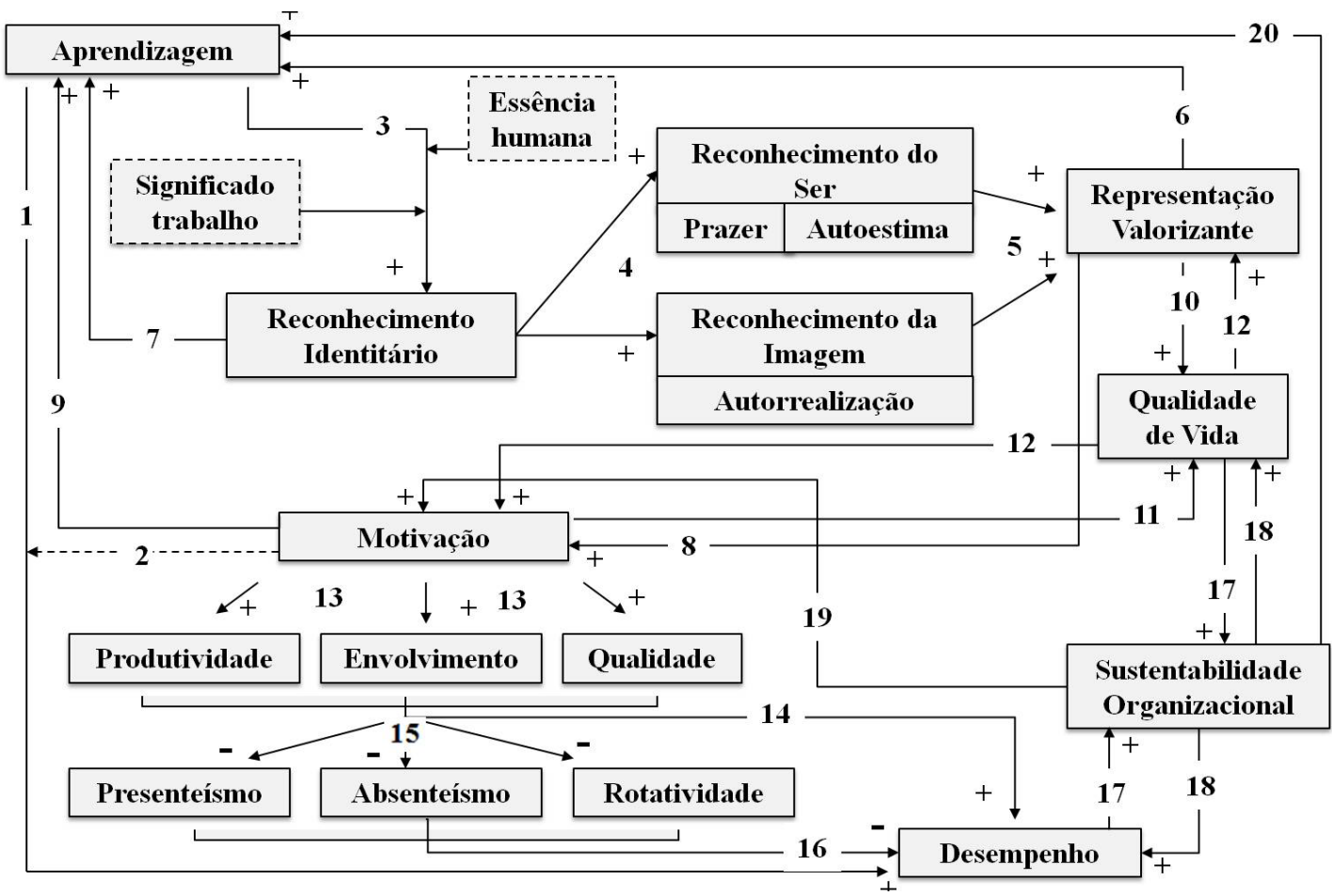

Figura 1- Mapa sistêmico Aprendizagem e Motivação

Fonte: Elaborada pelos autores

\subsubsection{A lógica do mapa}

O fundamento de tal representação, assim como de todos os mapas sistêmicos, tem como base hipóteses, intuições e o próprio conhecimento especializado acerca das relações recíprocas estabelecidas entre as variáveis. Vale a explicação de que as relações causais expostas no mapa sistêmico são diretamente proporcionais, quando representadas com o sinal (+), e inversamente proporcionais, quando representadas com o sinal (-).

Ao partir da principal variável de interesse do estudo, Aprendizagem, e a seguir a ordem direta das flechas, a primeira consideração a ser feita é concernente a sua relação com a variável Desempenho, trazida como a relação causal raiz (flecha 1 ). Como se nota, a causalidade entre ambas as variáveis é diretamente proporcional, uma exposição confirmatória da ideia de que o aprendizado consiste em uma estratégia de melhoria do desempenho no trabalho.

Com vistas a demonstrar o teor subjetivo desta relação causal raiz e analisar a atuação 
da variável Motivação como elemento intermediário da mesma (flecha 2), julgou-se necessário assumir como base as duas âncoras argumentativas expostas nos tópicos 3.2.1 e 3.2.2, a Essência humana e o Significado encoberto do trabalho. Trazidas como duas variáveis de influência, a consideração destas subsidia toda a lógica utilizada na construção e organização do mapa sistêmico.

Com base nelas, o primeiro fator que se estabelece é que a Aprendizagem consiste em um modelo de gestão que, ao mesmo tempo em que propicia a mobilização psíquica dos trabalhadores ao cumprimento de seus objetivos (flecha 1 ), garante o domínio dos critérios de Reconhecimento Identitário de cada um deles (flecha 3), uma vez que reconhece uma identidade individual e melhora a noção do autoconceito (MORETTI; TREICHEL, 2003).

Estes ideais são potenciais para a explicação da relação diretamente proporcional entre a Aprendizagem e o Reconhecimento Identitário. Levando em consideração a atuação do trabalho como fonte de significação e elemento de identificação pessoal, o fato de enriquecê-lo cognitivamente soa para o indivíduo como uma ação de reconhecimento de sua própria identidade. Isso porque, por meio da perceptível desvinculação do enfoque em resultados para uma valorização dos processos, o indivíduo receptor do novo conhecimento passa a encarar o aprendizado como um elemento que reforça seu próprio conceito e não como uma ameaça à autoestima (MORETTI; TREICHEL, 2003; SILVEIRA; MAIA; FIORAVANTI, 2012).

Assim, parafraseando os ideais de Morgan (2007), pode-se inferir que, uma vez que reconhece a identidade individual, o aprendizado aparece como um elemento reconhecedor da própria essência humana. Por desfrutar da satisfação das necessidades concernentes a sua natureza e da saciedade de suas demandas intrínsecas pelo desenvolvimento de competências, o fato de estar inserido em um processo de aprendizagem aumenta o teor da Autoestima do indivíduo, ao invés de ameaçá-la, e propicia condições favoráveis para maiores índices de Autorrealização e Prazer com aquilo que faz (flecha 4).

Isto significa que a aprendizagem, pelo próprio prazer intrínseco que submete ao indivíduo por meio da realização de algo novo e diferente, promove o florescimento do reconhecimento que o indivíduo tem de sua imagem e de si mesmo (GODOI; FREITAS; CARVALHO, 2011). Tal visão vai ao encontro da ideia de que, pela essencialidade que conferem aos seres humanos, uma vez combinados trabalho, capacitação e desenvolvimento pessoal, a execução de uma tarefa se torna uma fonte de dignidade e prazer, independentemente do contexto no qual esta combinação seja inserida (SILVEIRA; MAIA; FIORAVANTI, 2012).

Posto que o enriquecimento cognitivo e a atribuição de mais sentido naquilo que faz remetem a uma valorização daquilo que o indivíduo realmente é, as próprias funções cognitivas do mesmo o direcionam a um estado de Representação Valorizante (flecha 5), marcado pelas sensações de entusiasmo, gratificação e satisfação individual consequentes do favorecimento de suas necessidades humanas. Vale dizer que, de forma consequente a este estado emocional, as próprias atitudes que cuidam da aprendizagem são conjugadas e a subjetividade do indivíduo o permite investir ainda mais no aperfeiçoamento de suas competências performáticas, fazendo com que ele aprenda melhor e mais continuamente. Assim, o desenvolvimento das potencialidades humanas é aprimorado, redundando em um maior compromisso e produtividade (FONSECA, 2014; TÉLLEZ, 2012).

O trabalho de Salla (2012) fornece subsídios explicativos para a posição de Fonseca (2014) ao afirmar que, pelo fato da construção de sentido passar pela afetividade, o indivíduo dificilmente retém algo novo quando ele não o afeta. Deste modo, informações e acontecimentos que afetam e fazem sentido para o indivíduo ficam retidos na memória com mais facilidade e, assim, o esforço e a persistência em aprender são valorizados (MORETTI; TREICHEL, 2003). 
Este é um dos motivos pelo qual a variável Representação Valorizante, ao mesmo tempo em que aparece como um efeito da Aprendizagem (flecha 5), também exerce uma influência diretamente proporcional sobre ela (flecha 6). 0 mesmo ocorre com a variável Reconhecimento Identitário (flecha 7), também biunivocamente influente no aprendizado. Tais relações confirmam que os processos psicológicos são diretamente ligados ao processo de aprendizagem e podem tanto favorecê-lo quanto afetá-lo de maneira negativa (KIKUCHI; SALES; TARRAGÔ, 2013), visto que tal processo tem e assume um caráter afetivo e conativo.

Por essa razão, vale considerar que a aprendizagem dificilmente ocorre se o indivíduo estiver desfrutando de um período de sofrimento emocional ou de um estado psicológico desagradável, seja por uma ameaça identitária, por incompreensões ou por índices de autorrepresentação e autoestima negativos. Isso porque as funções conativas se fragilizam e, consequentemente, as funções cognitivas e executivas perdem a coerência e a sinergia, resultando em um processo de desfocagem atencional e um desinvestimento emocional (FONSECA, 2014).

Ao manter o raciocínio em direção à variável Motivação, pode-se afirmar que ninguém é capaz de motivar ninguém (GODOI; FREITAS; CARVALHO, 2011; KOFMAN, 2004; OSTERLOH; FREY, 2000). Contudo, considera-se que, uma vez que a Aprendizagem floresce a Representação Valorizante do indivíduo e as emoções humanas permitem que as ações inerentes ao processo sejam conjugadas, a subjetividade do indivíduo é enriquecida e ele, automaticamente, acaba sendo induzido a um estado de motivação intrínseca (FONSECA, 2014), trazida neste estudo como a principal manifestação do processo de aprendizagem na subjetividade humana (flecha 8) que atua na propensão individual em tirar vantagens da oportunidade para aplicação dos conhecimentos adquiridos (WEISSBEIN et al., 2011). Observa-se que o desencadeamento dos seus efeitos confirma que quanto maior o nível de enriquecimento cognitivo maior será a propensão individual à motivação (POOL, 2000).

Como se nota na representação, assim como as variáveis Reconhecimento Identitário e Representação Valorizante, a Motivação também se posiciona como um fator que alimenta o processo de aprendizagem e o desenvolvimento cognitivo das pessoas (flecha 9), levando em consideração o estado emocional do indivíduo e a afetividade requerida no mesmo (KIKUCHI; SALES; TARRAGÔ, 2013). Entende-se que um indivíduo cujo estado psicológico o motiva a aprender devotará tempo e colocará em prática o aprendizado independentemente de seu escopo (WEISSBEIN et al., 2011), provando que a categoria afetiva constitui o fator energético do fenômeno motivacional em direção a um objeto de conhecimento (GODOI; FREITAS; CARVALHO, 2011). Tais colocações confirmam que a subjetividade humana atua como determinante de sua motivação no e para o processo de aprendizagem (KLEIN; NOE; WANG, 2006).

Diante da favorável base sentimental e da satisfação das necessidades e aspirações constantes nas premissas da essência humana, vislumbra-se a questão da Qualidade de Vida no trabalho (flecha 10). Em outras palavras, resultantes de uma representação mais valorizada, a sensação de felicidade e bem-estar no trabalho são acrescidas. Da mesma forma, a Motivação também se porta como um fator influente neste processo, tendo em vista a abrangente noção comportamental que a considera como um poderoso meio de melhoria da qualidade de vida (flecha 11). Assim, como em um reforço mútuo, a própria melhoria na Qualidade de Vida do trabalho fomenta ainda mais estes sentimentos que a vislumbram, explicando a relação biunívoca entre eles (flecha 12) e, também, corroborando com a noção que a vê como sendo intimamente ligada aos fatores psicossociais (ABRAHÃO, 2014).

Objetivamente definida como o motivo para qualquer ação realizada por um sujeito, pode-se afirmar que é da Motivação que suscita todo o comportamento individual no trabalho. 
Sendo um processo psicológico responsável pelo aumento do teor de esforço para o alcance de objetivos, metas e resultados (KIKUCHI; SALES; TARRAGÔ, 2013), postula-se que um indivíduo mais motivado tende a ter um melhor Envolvimento (NAQUIN; HOLTON, 2002) e a desempenhar suas tarefas com maior Produtividade e Qualidade (flecha 13). Afinal, maior será o tempo e o esforço cognitivo alocado na monitoração do processo, no planejamento de melhorias e nos próprios ajustes nas estratégias de aprendizado (KLEIN; NOE; WANG, 2006).

Isso corrobora a visão amplamente difundida de que o processo de aprendizagem se reveste por um aperfeiçoamento no desempenho no trabalho (flecha 14) e que, na proposição deste artigo, a motivação intrínseca é o elemento que sustenta esse compromisso. Na medida em que tem um sentido especial para aquele que as executa, o próprio sentimento de autovalorização em relação às suas capacidades e potencialidades impulsiona o indivíduo a realizar suas tarefas da melhor maneira possível (TÉLLEZ, 2012).

Isso mostra que o fortalecimento das competências individuais relacionadas ao trabaIho, além de se portar como uma fonte de conhecimento, também consiste em uma fonte de eficiência e eficácia. A realização de uma atividade da qual o indivíduo detém o conhecimento e busca melhores formas de atuação produzirá melhores resultados e menores custos organizacionais (KIKUCHI; SALES; TARRAGÔ, 2013).

Como consequência de um estado motivacional favorável, denota-se que menores serão os índices de Presenteísmo, Absenteísmo e de Rotatividade na organização (flecha 15), já que, como problemas relacionados ao capital humano, são comumente associados aos fatores psicossociais (SILVEIRA, 2013a). A consideração desta relação é importante já que tais variáveis são consideradas fatores de prioridade no âmbito organizacional, tendo em vista a relação inversamente proporcional que estabelecem com o Desempenho empresarial (flecha 16).

Em méritos conceituais, a combinação do Desempenho organizacional com a Qualidade de Vida delimita a Sustentabilidade Organizacional (flecha 17), cuja ideia principal permeia a defesa da competitividade com qualidade de vida (SILVEIRA; BECARO, 2014). Deste modo, sua manutenção consiste em prezar por tal combinação exercendo influência direta sobre o desempenho, a qualidade de vida (flecha 18) e sobre a própria motivação (flecha 19), tendo em vista a sua crucialidade em todo o processo. É por este motivo que se considera a Sustentabilidade Organizacional como o fator que retroalimenta o processo de aprendizagem (flecha 20). O fenômeno abrange os benefícios do processo em termos subjetivos, graças ao vislumbrar da Qualidade de Vida, e em termos objetivos, por meio de seus reflexos no Desempenho da organização. Assim, valorizando os seus efeitos, valoriza-se a Aprendizagem.

Em síntese, pode-se enfatizar que, por meio de uma visão abrangente da representação sistêmica, confirma-se a inferência inicial de que os resultados objetivos do processo da aprendizagem aparecem como consequências da forma como a subjetividade humana é impactada por ele. Observa-se que o processo primeiramente beneficia o indivíduo, favorece o reconhecimento de sua identidade, de si mesmo e de sua imagem, satisfaz as necessidades condizentes a sua própria essência, subsidia a sua motivação intrínseca, para que assim reflita no seu desempenho.

Isso confirma a influência da afetividade no processo de aprendizagem. É o conceito que o indivíduo tem de si próprio que tem o potencial de afetar o seu nível de desempenho (FARIA, 2005). É por este motivo que vale trazer a colocação de Dejours (2004) que uma ação racional é aquela que se alimenta da noção de que toda a atividade de trabalho provém da subjetividade e aquela cujo principal objetivo é a celebração da vida. 


\subsection{ORIENTAÇÕES PARA GESTORES EDUCADORES}

Diante da demonstração da importância das relações entre a aprendizagem e a motivação, faz-se necessário o detalhamento do papel dos gestores, enquanto gestores educadores, como facilitadores das relações descritas no mapa sistêmico. Sabe-se que o gestor educador consiste em um novo perfil de gestor que, sem comprometer sua capacidade de gerenciar, seja aquele que se responsabilize em fomentar e compartilhar conhecimentos, aquele que coordena o capital intelectual. Entende-se que este profissional deve ter a capacidade de identificar as competências que precisam ser desenvolvidas considerando a função do trabalhador e o seu perfil, de forma que o processo de aprendizagem não seja algo homogêneo, mas dotado de sentido (SILVEIRA; MAIA; FIORAVANTI, 2012).

Com o intuito de traduzir toda a interpretação sistêmica entre aprendizagem e motivação como orientações a serem transmitidas para esses profissionais, ao relacionar tal perfil de gestão com os ideais do mapa, é válido ressaltar que o gestor educador deve levar em consideração toda a questão de sentido por detrás de algum enriquecimento na função, atentando-se ao perfil e aos valores do indivíduo. Como se nota, há uma consonância entre a missão de um gestor educador e a ideia central da representação sistêmica.

Assim, buscando traduzir os ideais expostos no mapa em alternativas práticas de ação da gestão, ao sustentar-se na ideia de que a aprendizagem é um processo afetivo e que só ocorre com o teor almejado quando o indivíduo convive em meio a um estado psicológico agradável, a primeira orientação a ser dada ao gestor educador é que o início de qualquer ação dentro deste mapa é naquilo que alimenta e que propicia a aprendizagem que mais tarde pode ser estimulada, a saber, o reconhecimento identitário, a representação valorizante e a motivação.

No entanto, por se tratarem de variáveis subjetivas, o gestor educador não tem poder nenhum sobre elas. Assim, a orientação é que toda a ação deve acontecer nas flechas do mapa sistêmico, promovendo condições para que tais variáveis floresçam nos indivíduos. Deste modo, cabe aos gestores educadores propiciar condições para o florescimento do reconhecimento identitário, da representação valorizante e da motivação no indivíduo, deixando-o em um estado favorável ao processo de aprendizagem, porque assim aumentam-se as chances de o aprendizado ser bem recebido.

Tratando-se de motivação, vale enfatizar que a motivação intrínseca é a mais importante para as organizações, visto que consiste em um elemento necessário para atividades que requerem criatividade e para se gerar e compartilhar conhecimento. Porém, ela não pode ser produzida por fatores externos, mas somente ocorre em condições favoráveis, seja por meio da participação do trabalhador nos processos organizacionais, pelo relacionamento pessoal, pela atribuição de sentido e significado ao trabalho que realiza, pelo sentimento de domínio do conhecimento, enfim, por aspectos que podem ser propiciados pela gestão educadora (OSTERLOH; FREY, 2000; PINK, 2010).

Como pode-se notar, tais visões permeiam os ideais explorados no mapa sistêmico acerca da causalidade entre o aprendizado e a motivação. Assim, observa-se que tudo é traduzido em uma necessidade de propiciar meios de reconhecer, valorizar e motivar os trabalhadores.

Para tanto, considera-se que a chave está no relacionamento entre gestor educador e trabalhador. Conforme apresentado no tópico 3.2.1, sabe-se que a demanda por competências é um elemento característico da essência humana e desempenha um papel central na vida dos seres humanos. Neste aspecto, cabe a consideração de que o indivíduo demanda inclusive competências de terceira dimensão, as quais se caracterizam não como habilidades manuais ou 
conhecimentos técnicos, mas qualidades pessoais e relacionais (SANT'ANNA; MORAES; KILIMNIK, 2005).

Diante disso, a orientação aos gestores educadores está em conhecer o trabalhador e relacionar-se continuamente com ele. Cabe a eles utilizar de uma estratégia de aproximação individualizada e procurar desvendar o sentimento e o sentido subjacente ao trabalho executado. Sabe-se que o indivíduo está ligado às organizações e ao trabalho por meio de laços inimagináveis, a ponto de fazer do seu espaço de trabalho o seu espaço pessoal (PAGÈS et al., 1987). Desta forma, conhecer cada um deles individualmente é o fundamento para que o gestor educador possa descobrir aquilo que compõe sua identidade, que sentido ele remete àquilo que executa, como ele se sente no trabalho e quais as suas necessidades e aspirações.

É fato que todas estas descobertas estão envoltas pela intangibilidade, mas tudo é manifesto pelo perfil comportamental de cada sujeito e pelos valores que norteiam seus comportamentos. O contato próximo com o indivíduo permite que o gestor educador identifique as nuances destes traços de forma que seja capaz de adotar uma estratégia de reconhecimento, valorização e motivação que faça sentido para o indivíduo e delimitar parâmetros para o enriquecimento cognitivo a ser promovido posteriormente.

Vale dizer que a delimitação de parâmetros é importante para que se alcancem os efeitos desejados em um processo de aprendizagem. É conhecendo o profissional que o gestor educador consegue estabelecer a forma, o conteúdo e a mídia a serem utilizados e identificar os limites de cada indivíduo ao aprendizado. Afinal, ultrapassando os limites individuais, o aprendizado poderá não ser bem recebido.

Além disso, conhecendo o trabalhador e relacionando-se com ele, o gestor educador consegue identificar quais os tipos de competências que lhe dão prazer e quais não dão prazer a este indivíduo. Muitos gestores falham em desenvolver competências considerando apenas os resultados em curto prazo, não sabendo que tais conhecimentos, habilidades ou atitudes podem não sustentar o prazer do indivíduo no longo prazo (TANURE, 2008). Por isso, conhecendo cada membro da sua equipe, o gestor educador pode evitar isso.

Da mesma forma, McCloy e Wise (2002) demonstram que a motivação para melhorar o trabalho por meio do aprendizado está relacionada substancialmente aos traços e características de tendência comportamental. Desta forma, as empresas que buscam melhorar a motivação para o aprendizado precisam conhecer esta relação, pois alguns indivíduos são mais propensos ao aprendizado do que outros.

Enfim, conhecer o indivíduo é essencial, porque é em sua subjetividade que se encontra a fonte de toda a ação. Quanto mais o gestor educador a conhece, mais profundamente poderá saber o que o motiva. Portanto, é desta forma que se consegue atingir o que é representado no mapa sistêmico. Por se tratar de uma representação que envolve variáveis individuais, a sua tradução varia para cada indivíduo. Mesmo sabendo que os fatores motivacionais que satisfazem o trabalhador são envoltos pelos ideais do reconhecimento, do crescimento, da realização e da responsabilidade, todos estão sob o controle intrínseco individual. Deste modo, conhecendo o indivíduo, o gestor educador tem meios para fazer com que cresça nas funções deste indivíduo o significado psicológico, adotando medidas de estímulo cognitivo que acabam fazendo com que ele sinta a sua identidade reconhecida, suas necessidades satisfeitas e intrinsecamente se motive com e para o trabalho.

Por conseguinte, uma vez identificada uma competência a ser desenvolvida em determinado trabalhador, o gestor educador pode contribuir para produzir nele um estado psicológico favorável para seu desenvolvimento. Ainda, pelo relacionamento construído, podem-se conhecer 
os meios para conduzir o processo de aprendizagem de maneira que ele caminhe enaltecendo ainda mais os seus efeitos e cumpra a lógica da representação sistêmica definida. $O$ fato de ter um relacionamento próximo com o trabalhador permite que o gestor educador o prepare para o aprendizado e para a transferência do conhecimento após o processo (WEISSBEIN et al., 2011).

Cabe ao gestor educador conscientizar-se de que o trabalhador é quem decide se vai aderir a um processo de aprendizado e contribuir para com os efeitos desejados ou não. Para tanto, o seu papel consiste em catalisar essa decisão. Empregar o indivíduo não é o suficiente e nem envolvê-lo em um processo de aprendizagem com a esperança de que vai ser capaz de acarretar todos os efeitos explícitos na representação sistêmica. O gestor educador deve propiciar condições adequadas para favorecer primeiro o lado afetivo, graças a sua crucialidade no processo de aprendizagem (KELLOWAY; BARLING, 2000).

Em síntese, vale enfatizar que o mapa sistêmico construído neste estudo é algo subjetivo. Portanto, não é o objetivo deste artigo apresentar métodos, formas e meios estabelecidos para traduzi-lo para os gestores educadores, mas enfatizar que conhecer cada profissional e propiciar condições para o florescimento de uma arena psicoagradável é o ponto de partida para que tudo se desdobre.

\section{CONSIDERAÇÕES FINAIS}

Respaldado por uma abordagem de cunho psicológico e sociológico, este artigo buscou analisar as principais relações estabelecidas entre a aprendizagem e a motivação no contexto organizacional. Para tanto, realizou-se um estudo bibliográfico de caráter exploratório e descritivo, visando fundamentar a construção de uma representação sistêmica que inclui as principais variáveis associadas à relação entre os dois fenômenos, denotando a natureza desta relação e a forma como, relacionados, impactam na produtividade do trabalho e no desempenho das organizações.

Com a realização do estudo percebeu-se que muito se é debatido acerca das questões relacionadas à aprendizagem no contexto organizacional, postulando-a como um modo de gestão que estabelece uma relação positiva com o desempenho do indivíduo na execução de suas tarefas. Porém, buscou-se enfatizar que a compreensão da essência desta relação requer um viés analítico subjetivo, considerando os efeitos que a aprendizagem gera no indivíduo de forma que influencie a propensão individual a uma melhoria de desempenho e ao próprio processo de aprender.

É válido considerar que a solidez do debate foi garantida ancorando-o a duas bases argumentativas presentes na literatura que, pela subjetividade analítica aqui proposta, foram julgadas como fatores influentes no processo abordado: a essência humana e o sentido encoberto do trabalho.

Portanto, em corroboração à ideia de que o processo de aprendizagem se reveste por um aperfeiçoamento no desempenho, tal fundamentação permitiu considerar a motivação intrínseca como o elemento que sustenta esse compromisso. Além de ser um estado psicológico do qual provêm os motivos, a força e a determinação para cada ação humana, a motivação engloba o interesse, o esforço, a persistência e o comprometimento afetivo com o aprender. Na medida em que tem um sentido especial para aquele que as executa, o próprio sentimento de autovalorização em relação às suas capacidades e potencialidades impulsiona o indivíduo a realizar suas tarefas da melhor maneira possível (TÉLLEZ, 2012).

Em síntese, pode-se dizer que o propósito do artigo de representar sistemicamente a 
relação entre os fenômenos foi pertinente pelo fato de que, por meio desta representação, ampliou-se a interpretação das relações causais e das influências recíprocas, direta ou inversamente proporcionais, entre as variáveis de interesse, oferecendo subsídios para tomadas de decisão e servindo como um meio de orientação aos gestores envolvidos nos processos de aprendizagem organizacional.

Há de se considerar que este artigo pode ser subsídio para novos estudos. Limitando-se ao delineamento segundo o que é fundamentado na literatura, o mapa sistêmico, com suas variáveis direta ou inversamente relacionadas, sugere sistemas de medição para as relações expostas no contexto organizacional onde elas realmente ocorrem. Além disso, diante de tantas variáveis subordinadas à subjetividade humana, sugere-se sua exploração por meio de lógicas matemáticas, como a Lógica Fuzzy, propiciando diferentes combinações entre as variáveis elencadas.

\section{REFERÊNCIAS}

ABRAHÃO, J. Prefácio. In: SILVEIRA, M. A; BECARO, T. C. (Orgs.). Competitividade com qualidade de vida: o capital humano como fator de produção. Campinas, SP: CTI (Centro de Tecnologia da Informação Renato Archer), 2014. p. 13-14.

BENDASSOLLI, P. F. Recomposição da relação sujeito-trabalho nos modelos emergentes de carreira. Revista de Administração de Empresas, São Paulo, v. 49, n. 4, p. 387-400, out./dez. 2009.

CHIUZI, R. M.; PEIXOTO, B. R. G.; FUSARI, G. L. Conflito de gerações nas organizações: um fenômeno social interpretado a partir da teoria de Erik Erikson. Temas em Psicologia, v.19, n. 2, p. 579-590, 2011. Disponível em: <http://bit.ly/1QrbuJh>. Acesso em: 17 dez. 2015.

DEJOURS, C. Subjetividade, trabalho, ação. Revista Produção, v. 14, n. 3, p. 27-34, set./dez. 2004.

FARIA, L. Desenvolvimento do autoconceito físico nas crianças e nos adolescentes. Análise Psicológica, Lisboa, v. 4, n. 23, p. 361-371, 2005.

FONSECA, V. da. Papel das funções cognitivas, conativas e executivas na aprendizagem: uma abordagem neuro psicopedagógica. Revista Psicopedagogia, São Paulo, v. 31, n. 36, p. 236-253, 2014.

GIL, A. C. Como elaborar projetos de pesquisa. 4. ed. São Paulo: Atlas, 2002. 
GODOI, C. K.; FREITAS, S. M. F. de.; CARVALHO, T. B. Motivação na aprendizagem organizacional: construindo as categorias afetiva, cognitiva e social. Revista de Administração Mackenzie, São Paulo, v. 12, n. 2, p. 30-54, mar./abr. 2011.

KELLOWAY, E. K.; BARLING, J. Knowledge work as organizational behavior. International Journal of Management Reviews, v. 2, n. 3, p. 287-304, set. 2000.

KIKUCHI, L. S.; SALES, E. A.; TARRAGÔ, R. M. Enriquecimento cognitivo para desenvolvimento da inovação e do potencial humano. In: SILVEIRA, M. A. et al. Inovação para desenvolvimento de organizações sustentáveis. Campinas, SP: CTI (Centro de Tecnologia da Informação Renato Archer), 2013. p. 31-43.

KLEIN, H. J.; NOE, R. A.; WANG, C. Motivation to learn and course outcomes: the impact of delivery mode, learning goal orientation, and perceived barriers and enablers. Personnel Psychology, $v$. 59, p. 665-702, 2006.

KOFMAN, F. Metamanagement: o sucesso além do sucesso. Rio de Janeiro: Elsevier, 2004.

MCCLOY, R. A.; WISE, L. L. Invited reaction: the effects of personality, affectivity, and work commitment on motivation to improve work through learning. Human Resource Development Quarterly, v. 13, n. 4, p. 377-382, 2002.

MORETTI, S.; TREICHEL, A. Qualidade de vida no trabalho $x$ auto-realização humana. Revista Leonardo pós-Órgão de Divulgação Científica e Cultural do ICPG, Blumenau, v.1, n. 3, p. 73-80, 2003.

MORGAN, G. Imagens da Organização. 2. ed. São Paulo: Atlas, 2007.

NAQUIN, S. S.; HOLTON, E. F. III. The effects of personality, affectivity, and work commitment on motivation to improve work through learning. Human Resource Development Quarterly, v. 13, n. 4, p. 357-376, 2002.

OSTERLOH, M.; FREY, B. S. Motivation, knowledge transfer, and organizational forms. Organization Science, v. 11, n. 5, p. 538-550, set./out. 2000.

PAGÈS, M. et al. O poder das organizações. São Paulo: Atlas, 1987. 
PARKER, S. K. Enhancing role breadth self-efficacy: the roles of job enrichment and other organizational interventions. Journal of Applied Psychology, v. 83, n. 6, p. 835-852, 1998.

PINK, D. Motivação 3.0. Rio de Janeiro: Ed. Campus Elsevier, 2010.

POOL, S. W. The learning organization: motivating employees by integrating TQM philosophy in a supportive organizational culture. Leadership \& Organization Development Journal, v. 21, n. 8, p. 373-378, 2000.

ROCHA-DE-OLIVEIRA, S.; PICCININI, V. C.; BITENCOURT, B. M. Juventudes, gerações e trabalho: é possível falar em geração Y no Brasil?. Organizações \& Sociedade, Salvador, v. 19, n. 62, p. 551558, 2012. Disponível em: <http://bit.ly/1NUMVlr>. Acesso em: 17 dez. 2015.

SALLA, F. Toda a atenção para a Neurociência. Nova Escola, São Paulo, n. 253, jun./jul. 2012. Disponível em: <http://abr.ai/109H93E>. Acesso em 15 dez. 2015.

SANT'ANNA, A. de S.; MORAES, L. R. F. de; KILIMNIK, Z. M. Competências individuais, modernidade organizacional e satisfação no trabalho: um estudo de diagnóstico comparativo. Revista de Administração de Empresas, São Paulo, v. 4, n. 1, jan./jul. 2005.

SANTOS, P. De bem com o trabalho. Vida Simples, São Paulo, v. 162, p. 20-27, set. 2015.

SENGE, P. Prefácio. In: KOFMAN, F. Metamanagement: o sucesso além do sucesso. Rio de Janeiro: Elsevier, 2004.

SENGE, P. The leader's mew work: building learning organizations. Sloan Management Review, v.32, n.1, p. 7-23, 1990.

SILVEIRA, M. A. Gestão estratégica para a sustentabilidade organizacional: capital humano e os processos de inovação e aprendizagem. In: SILVEIRA, M. A. (Org.) Gestão da sustentabilidade organizacional: inovação, aprendizagem e capital humano. Campinas, SP: CTI (Centro de Tecnologia da Informação Renato Archer), 2012. p. 21-46.

Organização saudável, desenvolvimento sustentável: construindo convergência entre lucro econômico e desenvolvimento humano. In: In: SILVEIRA, M. A. et al. Inovação para desenvolvimento de organizações sustentáveis. Campinas, SP: CTI (Centro de Tecnologia da 
Informação Renato Archer), 2013a. p. 15-29.

Strategic Management of Innovation Towards Sustainable Development of Brazilian Electronics Industry. Journal of Technology Management \& Innovation, v.8, p.174-183, 2013b.

SILVEIRA, M. A., BECARO, T. C. Competitividade com qualidade de vida: estratégias e práticas baseadas na valorização do fator humano nas organizações. In: SILVEIRA, M. A; BECARO, T. C. (Orgs.). Competitividade com qualidade de vida: o capital humano como fator de produção. Campinas, SP: CTI (Centro de Tecnologia da Informação Renato Archer), 2014. p. 21-37.

SILVEIRA, M. A. et al. Inovação e aprendizagem organizacional: abordagem TCD para desenvolvimento de competências em empresa do setor eletrônico. In: CONGRESSO LATINOIBEROAMERICANO DE GESTÃO DE TECNOLOGIA, 16., 2015, Porto Alegre. Anais ALTEC. Porto Alegre, 2015. Disponível em: <http://bit.ly/10a4HDk>. Acesso em: 17 dez. 2015.

SILVEIRA, M. A.; MAIA, L.; FIORAVANTI, M. Aprendizagem organizacional para a sustentabilidade: integração ao trabalho e valorização do fator humano. In: SILVEIRA, M. A. Gestão da sustentabilidade organizacional: inovação, aprendizagem e capital humano. Campinas, SP: CTI (Centro de Tecnologia da Informação Renato Archer), 2012. p. 163-180.

TANURE, B. Sofrimento transitivo. GVexecutivo, São Paulo, v. 7, n. 6, p. 62-67, nov./dez. 2008.

TÉLLEZ, J. A. V. Implicaciones de la teoría motivacional de la autodeterminación en el ámbito laboral. Revista Electrónica Nova Scientia, León, v. 5, n. 9, p. 154-175, 2012. Disponível em: <http://bit.ly/10a5wvW>. Acesso em: 17 dez. 2015.

VELOSO, E. F. R.; SILVA, R. C. da; DUTRA, J. S. Diferentes gerações e percepções sobre carreiras inteligentes e crescimento profissional nas organizações. Revista Brasileira de Orientação Profissional, Ribeirão Preto, v. 13, n. 2, p. 197-208, 2012. Disponível em: <http://bit.ly/1m9BHPm>. Acesso em: 17 dez. 2015.

VERGARA, S. C. Projetos e relatórios de pesquisa em administração. 11. ed. São Paulo: Atlas, 2009.

WEISSBEIN, D. A. et al. Influencing learning states to enhance trainee motivation and improve training transfer. Journal of Business and Psychology, v. 26, p. 423-435, 2011.

Rev. AdM. UFSM, SANTA MARIA, V. 11, NÚMERo 5, P. 1222-1239, 2019 